\title{
Máscaras y mascaradas de Carnaval en Sierra Morena
}

Las publicaciones que tratan del Carnaval andaluz suelen referirse, generalmente, a un tipo de Carnaval urbano, de gran prestigio y vigencia, como el de Cádiz y otras grandes poblaciones, sobre todo costeras. En cambio, es raro encontrarse informes detallados sobre lugares más pequeños y agrestes. La colección de máscaras y mascaradas que aquí traigo pertenece, precisamente, a este otro tipo de Carnaval, rústico y de aire más arcaico, sobre el que quiero llamar la atención por sus semejanzas con el viejo Carnaval campesino de otras latitudes españolas y de Europa.

En 1980, tras la lectura de la magistral obra de Caro Baroja, El Carnaval $^{1}$, comencé a recolectar los primeros datos en la aldea Arroyo de la Plata (Sevilla). A pesar de que estas fiestas habían desaparecido, desde 1936 aproximadamente, las personas que me informaron (nacidas en los primeros veinte años del siglo) me traían un mundo, en ciertos aspectos, muy semejante al del libro que me servía de guía. Esto causó en mí no poca sorpresa, y continué recogiendo datos sobre el Carnaval (y otras fiestas populares) en aldeas y pueblos situados en las provincias de Huelva y Sevilla, sobre todo en los que están ya en Sierra Morena. Ahora presento aquí esta pequeña colección.

\section{RELACIÓN DE MÁSCARAS Y MASCARADAS}

\section{Arroyo de la Plata (Sevilla)}

A) Tres personajes: el primero iba enmascarado y con una capa. Bajo ella ocultaba un cuerno que hacía asomar de forma obscena, al tiempo que decía: "lo que va debajo la capa, poco se escapa", que interpreto: "de lo que va debajo de la capa pocos escapann. El segundo iba también enmascarado y portaba dos "liaras" ${ }^{2}$. Pasaba "agua sucia" de un cuerno a

1 Julio Caro Baroja, El Carnaval. Análisis histórico cultural (Madrid: Taurus, 1979, 2. ${ }^{2}$ ed.).

2 .Liara. o dllavero", cuernos donde se guardaba el aceite y el vinagre, unidos por una cadenilla. 
otro, diciendo: "No digas: de este agua no he de beber. Puede ser que te obligue la sed. El tercero, igualmente enmascarado, llevaba un harnero y hacía, con muchos meneos, como si estuviese limpiando el trigo en la era. Decía al mismo tiempo: "AAhecho, ahecho!n. Todo esto era interpretado como una obscenidad ${ }^{3}$.

B) Poseo varios informes sobre la mascarada del oso en Arroyo de la Plata. Por uno de ellos sé que bajaban hasta la aldea, desde un cortijo cercano, dos hombres. Uno vestido de oso, a base de zaleas, y otro que lo llevaba amarrado, haciéndolo saltar y bailar. Al mismo tiempo hacía ruido con una lata.

Otro informe habla de que el oso iba con la cara tiznada y una alpargata a cada lado de la cabeza, simulando las orejas. Estaba cubierto de zaleas y con él iba otro personaje que lo llevaba amarrado por la cintura (porque el oso debía comportarse con gran ferocidad). En todos los bailes de Carnaval, por la noche, aparecía el oso; bailaba y, de repente, se abalanzaba sobre las mujeres. A veces, cuando éstas estaban jugando a los "candelones", cogidas de la mano y haciendo corro, entraba el oso y lo desbarataba todo, e iba tras ellas. Cogía a alguna y se revolcaba con ella por el suelo.

Según un último informe, el oso llevaba una "corcha" en la espalda, debajo de las pieles, donde le daba fuertes y sonoros golpes con un palo el que lo conducia, que lo llevaba atado con una cadena. Los dos personajes iban haciendo cuestación de casa en casa. Les daban chorizos, huevos, etc., para una ufritada".

C) Las mujeres iban, frecuentemente, con ropa antigua: con un "polipón" ${ }^{4}$. Estas ropas antiguas se sacaban de los arcones para la ocasión, y se prestaban.

\section{Valdeflores (Sevilla)}

A) Las mujeres se disfrazaban de "Serranas", "Pravianas" y "Cazurras" ". Estos disfraces se consideraban hermosos, para que las mujeres se lucieran

\footnotetext{
" "Ahecho", con "hn aspirada. Expresión modal que significa "todo a la vez, sin dejar nada atrás.. Ya viene recogida en el Diccionario de Autoridades. "Harnero" también se pronuncia con "h" aspirada. El sentido de la mascarada se puede ver más claro en la nota 12.

+ ¿Polisón?

" El disfraz de "Praviana. solía llevar una cesta de flores y la muchacha que lo vestía iba diciendo: "Flores, p'al mal de amores". "Serranas", "Pravianas" y "Cazurras" salían también en Nerva (Huelva).
} 
en el baile de Carnaval. De ellos existen fotografías. También se solían disfrazar de gitanas, con sartén y "estrébede o trébede para usar en una comida que se organizaba en el campo. O de ciega o ciego de romance, con su lazarillo ${ }^{6}$. O de loca ${ }^{7}$.

B) Mascarada del oso: un mozarrón se disfrazaba de oso, con pellejos de vaca y zaleas de cordero. Debajo de ellos llevaba una "corcha", en la espalda, donde soportaba los golpes que otra máscara le daba con un palo. Alzaba las manos y emitía fuertes gruñidos. Una gruesa cadena le unía con su dueño.

\section{Villargordo (Sevilla)}

A) Las máscaras salían todos los días, desde el Domingo de Carnaval hasta el Domingo de Piñata, disfrazándose del sexo contrario. Las mujeres con pantalones (cosa vista con gran extrañeza entonces) o "zagalejos" ${ }^{8}$. A veces, con zahones de becerro y con botas altas. Los hombres iban con un canasto en el culo y "naguas".

B) Mascarada del oso: un hombre con zaleas en el cuerpo y "corchas" en la espalda, por debajo de ellas, para aminorar las golpes que le daban. A veces, andaba a cuatro patas. Cada vez que le pegaba su amo (que lo llevaba tirando de una cuerda), se levantaba y gruñía. Iban pidiendo de casa en casa dinero, chorizos, etc.

\section{El Castillo de las Guardas (Sevilla)}

A) Mascarada del oso: como en Arroyo de la Plata.

\section{El Cañuelo (Sevilla)}

A) Mascarada del oso: durante todo el Carnaval, desde la mañana hasta el mediodía, solían salir dos hombres haciendo cuestación de casa en casa. Uno vestido con pieles y una "corcha" debajo de ellas, en la

6 Recitando: „Santa Lucía bendita, madre de los desgraciados, dale vista a esta ciega que el demonio se la ha quitado.

7 Con el cabello suelto, "sobrecorsé", y con el cuerpo rayado con lápiz rojo, imitando sangre.

8 "Naguas* o enaguas rojas, antiguas, hechas de buena fábrica, semejante al de algunas colchas, según mis informantes. 
espalda, para soportar los golpes del que hacía de dueño, que lo llevaba atado con una cadena. Este hacía bailar al oso delante de cada puerta. A veces, el oso se abalanzaba sobre las mujeres, emitía gruñidos... En cada casa les daban naranjas, chorizos, huevos, etc., para una cena.

B) Las escenas tradicionales burlescas, representadas por un grupo de máscaras, generalmente en el baile de Carnaval, por la noche, eran conocidas con el nombre de ajuegos de Carnaval. Así también en Arroyo de la Plata ${ }^{9}$. Una de ellas consistía en un diálogo ridículo entre un cura y un cabrero muy bruto al que aquél trata de confesar.

C) Otra, que también se conocía en Arroyo de la Plata, eran dos máscaras; una que representaba a una vieja gruñona y la otra a su joven criada. La vieja importuna constantemente a la criada con muchas órdenes, entre las que siempre se citan:

"iLa pipa!n (es decir, "tráeme la pipa", porque se conoce que la vieja fumaba).

“-iLa porra!n (un bastón).

-iA la puerta llaman!n.

Así, hasta la desesperación de la criada, que acaba a escobazos con la vieja.

D) Otro ajuego de Carnaval" era como sigue. Dos máscaras. Una quiere comprar un burro a la otra. La tercera máscara era la del burro, hombre que iba a cuatro patas y cubierto completamente por una manta que le caía hasta el suelo. Por debajo de ella salía el cabestro. Un extremo lo tenía asido el dueño del burro, y el otro estaba atado a una "bacinilla" u orinal (lleno de vino blanco y morcillas) que ocultaba el burro debajo de su manta. Mis informantes cuentan que se necesitaba también algún forastero que asistiera al baile, o, en su defecto, alguna persona de pocas luces, para hacerle blanco de la broma. Las dos primeras máscaras se disponen al trato para la compraventa del animal, teniendo siempre el dueño el ronzal de su mano. Comienzan entonces las conocidas vueltas y revueltas de estos negocios, que dan pie a la risa, frecuentemente. De pronto, los tratantes deciden continuar en la barra del bar y preguntan al público y a la persona elegida como objeto de la broma:

- ¿Quién quiere cuidar de que este burro no se escape? Pero, cuidado, este burro es muy malo; siempre quiere escaparse. No hay manera de sujetarlo, etc.

El incauto se ofrece a recoger el cabestro. En algunos casos, incluso asegura que no se le podrá escapar... Cuando los tratantes marchan de-

9 En Almadén de la Plata (Sevilla), la expresión ajuegos de Carnaval- era sinónimo de baile de Carnaval. 
cididos al bar, el burro, dando una «espantá», se escapa, dejando al engañado con un extremo del cabestro en la mano, y en el otro la "bacinilla", al descubierto, llena de "porquerías".

\section{El Peralejo (Sevilla)}

A) La misma escena anterior de los tratantes se conocía en El Peralejo, pero con un oso en vez de un burro. Mi informante dice que "cogían a la más tonta del baile para que agarrase la cuerda del oso. El oso salía corriendo y ella se quedaba con el orinal" ${ }^{10}$.

\section{La Alcornocosa (Sevilla)}

A) Mascarada del oso: como en Valdeflores. Iba de puerta en puerta haciendo cuestación.

B) Mis informantes me han hablado de dos "juegos de Carnaval", pero ninguno de ellos recuerda más detalles que los que aquí refiero. En el primero, unos "barreneros" de la mina, tapados con una manta, terminaban quedándose con un orinal que estaba escondido. En el segundo, uno simulaba entrar en una viña a comer uvas a dos carrillos, repartiéndolas a discreción entre los asistentes al baile.

\section{Santa Olalla del Cala (Huelva)}

A) Las mujeres se vestían de "ropas antiguas", o de gitanas o cigarreras.

B) Una mujer hace de muerta tumbada en una escalera que, a modo de camilla, llevaban otras dos. Con la cara tiznada, con muchas trencitas y lacitos en el pelo, otra mujer pedía lastimosamente: " Una "perrita" para poder enterrar a mi hija que se me ha muerto!n.

C) Mascarada del oso: un hombre con la cara tiznada, a modo de máscara, llevaba dos zaleas, una por delante y otra a la espalda, amarradas a la cintura con una cuerda. Del cuello, una cadena. También vestía unos pantalones cortados y aflecados y calzaba unas botas rotas. Otra máscara era el dueño del oso, que pasaba el platillo para que la gente echara monedas, mientras el oso mostraba sus habilidades.

10 Los informantes de Valdeflores (Sevilla) me hacen saber que en El Peralejo tenían fama las mascaradas, y que debe quedar aún gente mayor de edad que sepa de muchas. 
D) Un hombre vestido con una capa de paño, antigua, grande. Debajo de ella llevaba unos cuernos. Otra máscara con un harnero para "horear" el trigo ${ }^{11}$. El primero sacaba los cuernos por debajo de la capa con gesto obsceno y se los ponía en la cabeza, y hacía como el toro al embestir. Al mismo tiempo decía: "Lo que va debajo de la capa, nada se escapan. El del harnero decía: “Ahecho, ahecho!n, al tiempo que, con muchos meneos, ejecutaba los movimientos propios de ahechar o cribar el trigo ${ }^{12}$.

\section{El Ronquillo (Sevilla)}

A) Mascarada del oso: un hombre con zaleas y un "ropón" ${ }^{13}$ que iba "haciendo el oso"; la otra máscara era "el que lo lleva domado".

B) Las muchachas se vestían de "Serrana", con un vestido ancho, y de "Cazurra"; así iban al baile donde los muchachos les daban "chotes" $\mathrm{o}$ golpes en las piernas con unas varas finas, con la intención de que "saltaran y se les vieran las piernas", según dice el informante. Esta costumbre era conocida con el nombre de "jugar a refajitos cortos". También era propio del baile de Carnaval que ellas quitaran los sombreros a los muchachos quienes, para recuperarlos, debían pagar una "convidá".

\section{COMENTARIOS}

Voy a dividir los comentarios a esta pequeña colección de máscaras y mascaradas de Carnaval en cinco apartados: los dos primeros estarán dedicados a la mascarada del oso y del burro. En tercer lugar a los disfraces de "Serrana", "Praviana" y "Cazurra"; después los "juegos de Carnaval, con sus diversas representaciones tradicionales. Finalmente, un apartado con máscaras variadas y algún aspecto de alguna mascarada digna de comentario.

1) La mascarada del oso es conocida por todos mis informantes.

Una exactamente igual que las descritas salía en Arizcun, en el valle de Baztán (Navarra), y en toda la zona de la Vera (Cáceres) ${ }^{14}$. Pío Baroja

1 "Horear", con th" aspirada. Limpiar el trigo en el harnero.

12 La expresión "ahecho" no se entiende como del verbo ahechar. Mi informante dice, entre risas, que aquí significa que la máscara del harnero tha hecho a todas las mujeres putass, pero a todas, sin excepciones, que es lo que subraya el sentido local de esta expresión que ya vimos en la nota 3.

13 Manta vieja, grande, de abrigo.

14 Según una ponencia presentada por Guadalupe GONZÁLEZ-HONTORIA y OTROS, •El animal como protagonista en los Carnavales espanoles* en el Coloquio Internacional 
habla también de una igual ${ }^{15}$ y Ramón Violant i Simorra la recoge en Sarroca de Bellera, donde salía desde San Antonio Abad (17 de enero) hasta Carnaval. Y en Espuy (valle de Capdella), Son del Pino, Espot, Ferrera y Rialp (en Lérida y Gerona) en el día de Carnaval solamente, señalando que en el Ampurdán había costumbres parecidas ${ }^{16}$. En Huesca (Bielsa, Sobrarbe) el día 2 de febrero y en Carnaval, sale una máscara de oso que es fustigada por otra máscara con cuernos ${ }^{17}$. En Andalucía, entre las provincias de Córdoba y Sevilla, en la aldea de Fuente Carreteros ${ }^{18}$ salía el día 29 de diciembre (es decir, el día después del de Inocentes) un oso ataviado con los mismos elementos que los de mi informe y al que le daba palos en la espalda el que lo llevaba atado. El oso, muy relacionado con una danza de "locos", se revolcaba en el barro o bailaba, mientras que los que habían hecho de "locos" el día anterior en la danza, recogían dinero para el vino que se bebería en una comida especial.

En Francia, así como en la zona más oriental de España desde el País Vasco, aparecía también frecuentemente esta mascarada, aunque insistiendo más en el rasgo de la caza del oso. Caro Baroja, en El Carnaval ${ }^{19}$, habla de la caza del oso de Amélie-les-Bains, el día de la Candelaria. También en el Ampurdán, en otras fechas. En Andorra el día de la Purificación de Nuestra Señora y el Domingo de Carnaval se representaba la caza y el baile del oso y la osa. En el País Vasco salía también un oso que robaba corderos y era cazado por unos gitanos ${ }^{20}$. En el trabajo, ya citado, de Guadalupe González-Hontoria et al. ${ }^{21}$ se hace referencia a esta

sobre el Carnaval, la fiesta y la comunicación que se celebró en Niza en 198: Actes de Rencontres Internationales de Nice (Editions Serre, UNESCO); en español en la revista Narria, núms. 31 y 32.

15 Pío BAROIA NESSI, "Los demonios del Carnaval" en Vitrina Pintoresca, Ohras Completas (Madrid, 1948), V, p. 821. Y también Julio Caro Baroja, "Una fiesta de buena vecindad", RDTP, XXVI (1970), pp. 14 y 15 y fig.7, donde describe unas mascaradas de Ituren (Navarra) en las que sale un oso. Advierte que eel oso es animal popularísimo en las mascaradas de invierno europeas y concretamente en las pirenaicas".

16 ViOlant I SimORRA, Ramón, El Pirinero español (Barcelona: Ed. Alta Fulla, 198), II, p. 572.

17 J. Roma RiU, Aragón y el Carnaval (Zaragoza: Guara editorial, 1980), pp. 71, $80,108$.

18 F. LUQUe-ROMERO y J. COBOS, "Las danzas religiosas masculinas en la provincia de Córdoban, Antropología cultural de Andalucia (Sevilla: Consejería de Cultura de la Junta de Andalucía, 1984), pp. 423 y 424.

19 Op. cit., p. 263.

20 Op. cit., pp. 180 y 187.

21 G. GONZÁlez-HONTORIA y OTROS, op. cit., p. 6. 
misma mascarada en el Pirineo en general y en Andorra en particular. Violant indica que la caza del oso se escenificaba en Andorra y en Vallespir ${ }^{22}$. El mismo Caro Baroja, en las notas de un viaje por Murcia, hecho por 1950, apunta una mascarada de Carnaval en que un hombre que se disfrazaba de oso era apresado y conducido al pueblo atado con una cadena ${ }^{23}$. En Asturias están recogidas por Constantino Cabal y otros ${ }^{24}$ como personajes bien conocidos en las "zamarronadas", o entre los llamados "guirrios", "esterones", etc. El oso persigue a la gente, baila, participa en riñas o en "comediejas de color y sabor insustanciales" ${ }^{25}$. También los podemos encontrar en Santander ${ }^{26}$ como tipos consabidos entre las máscaras que salen a fin de año haciendo cuestaciones para una comida el día de Reyes. Incluso en "El Entierro de la Sardina" de Goya, entre la turbamulta de máscaras, en el ángulo inferior izquierdo, se puede ver una máscara de oso.

Por lo que se refiere a los otros países europeos tenemos información gráfica de estas máscaras y mascaradas en el libro Carnavals et mascarads ${ }^{27}$, procedentes de Rumanía, Francia, Austria, Bohemia y Polonia. Caro Baroja informa de paseos de osos de paja en Inglaterra, Bohemia, etc. ${ }^{28}$. En resumen, la mascarada del oso, con más o menos variaciones, es conocida en un área muy extensa de Europa. En España parece adoptar dos modos: al oriente es más común simular su caza y en el occidente no, aunque no faltan casos. A pesar de que conozco algún ejemplo aislado ${ }^{29}$, no parece propia del centro. Las que yo he recogido se asemejan a las más comunes en el occidente de España.

2) Veamos ahora otra mascarada igualmente importante. Se trata de la representación burlesca de la venta de un burro que, al final, escapa,

22 Ramón Violant I Simorra, op. cit., pp. 572 y 573.

2.3 Julio CARO BAROJA, Apuntes murcianos. (De un diario de viajes por España. 1950) (Murcia: Universidad de Murcia, 1984, 2." ed.), p. 36.

24 Constantino CABAL, Contribución al Diccionario folklórico de Asturias, (Oviedo: Diputación de Asturias. Instituto de Estudios Asturianos, 1955 y 1958), Voz "Antroxu", pp. $105-213$.

25 La frase es de Constantino Cabal, citada por CARO BAROJA, El Carmaval, op. cit., p. 218.

26 J. Caro Baroja, el Camaval. op. cit., p. 236.

2- V. AA., Carnavals et Mascarades, sous la direction de P. Giovanni d'Ayala et Martine Boiteux (París: Ed. Bordas, 1988). Rumania, p. 23; Bigorre (Francia), 79-80; Paris, 62; Lötschental, 96; Austria, 116; Bohemia, 121; y Polonia, 124. Asturias.

28 J. Caro Baroia, el Camaval, op. cit., pp. 263, 264, 265, 282. Y también en

29 Lastras de Cuéllar (Segovia), según GonzÁlez-Hontoria y otros, op. cit., p. 6. 
y que he hallado en El Cañuelo (Sevilla). De forma parecida (aunque en este caso se trata de un oso) aparecía durante el Carnaval en El Peralejo (Sevilla) y alguna adaptación de esta escena debió de representarse también en La Alcornocosa (Sevilla) en los llamados ajuegos de Carnaval.

La misma venta burlesca de una mula se escenificaba en Sarroca de Bellera (Lérida) el Domingo de Carnaval, según los datos de Violant ${ }^{30}$, y, además, en Bellanos, Esterri de Aneo, Espot e Isil, lugares del Pirineo, donde se encuentra el mismo disfraz conocido con el nombre de "la mula blanca. Algo también muy parecido se daba en el valle de Polaciones (Santander) ${ }^{31}$. Informes semejantes podemos hallar en el libro de Nicolás Tenorio, La aldea gallega ${ }^{32}$, publicado a principios de siglo en Cádiz. La mascarada era conocida en ciertas aldeas orensanas con el nombre de "la mula y el maragato". Dos hombres hacen de mula, que es conducida por un "maragato". El animal da coces y sólo acepta que lo monten ${ }^{33}$ con la condición de que inviten en la taberna. También se pone enferma, pero sana con vino. Finalmente intentan herrarla, pero escapa dando coces.

No es difícil encontrar más mascaradas que se centran en un animal similar.

Según Caro Baroja, en la montaña de León eran propias de Carnaval las "zafarronadas" en las que solía salir "la mula ciega" ${ }^{34}$. En otro lugar se citan máscaras de burras en comarcas de Asturias ${ }^{35}$ y de mulas en Pola de Allende ${ }^{36}$ a primeros de año. El mismo Caro Baroja relaciona estas mascaradas de burros o mulas con las que se hacen en otros sitios, aproximadamente en las mismas fechas, aunque se trate, esta vez, de la figura de un caballo. En el País Vasco es famoso "Zamalzain", de las

\footnotetext{
30 R. VIOLANT I SimorRa, op. cit., p. 572.

31 Fernando Gomarín Guirado, *El Carnaval en un valle de la Cantabria suroccidental, Revista de Folklore, 5, 1985, pp. 93-107.

32 Nicolás TEnorio, La aldea gallega (Cádiz, 1914), con informes de lugares pertenecientes al Partido Judicial de Viana del Bollo (Orense). Yo lo leo en Ediciós Xerais de Galicia, Vigo, 1982.

33 .Especialmente a las mozas - procurando tirarles al suelo o llevarles a la cantina para pagar una cantidad de vinon. GonZález-Hontoria y otros, op. cit., p. 6.

${ }^{34}$.Que es un individuo que se coloca sobre los hombros de otros dos; van tapados con dos colchas de camas y no se ve dónde terminan los unos ni dónde comienza el otro. El de arriba lleva una cabezada y los de abajo u otro de la comitiva hace como que tira del cordel. El que va encima llega con las manos a ventanas y balcones.. Según César Morán al que cita Caro Baroja en El Carnaval, op. cit., p. 231.
}

Caro Baroja, El Camaval, op. cit., p. 218.

36

Caro Baroja, El Camaval, op. cit., p. 219. 
complejas mascaradas carnavalescas suletinas, o "zaldiko" en el Carnaval de Lanz ${ }^{37}$. En ambos casos las máscaras intentan herrar al caballo fingido y lo consiguen, no sin emplear la fuerza. En las suletinas lo castran, y el animal parece perder fuerza para tomar enseguida nuevos bríos. En Aragón (Bielsa, Huesca), es conocida con el nombre de "amontato una máscara compuesta de caballo y jinete fingidos, llevados por un hombre ${ }^{38}$, todo ello con "significación erótica" ${ }^{39}$. Más máscaras que representan caballos podemos hallar en Francia, Inglaterra ${ }^{40}$, Bulgaria y los Balcanes ${ }^{41}$. Entre las máscaras carnavalescas conservadas en el Schweizerischer Museum für Volkskunde de Basilea (Suiza), aparece también una de caballo ${ }^{42}$.

En fin, también aquí nos encontramos con que estas mascaradas del burro que he documentado se asemejan a otras que salían, en las mismas épocas del año, en áreas extensas de Europa desde muy antiguo. Pero si las comparamos con las que aparecen o aparecían en una zona muy concreta de nuestro país (Galicia, Asturias, Santander, País Vasco y el Pirineo) podremos hallar más que semejanzas.

3) Prestemos ahora atención a los disfraces llamados de "Serrana", "Praviana" $O$ "Cazurra", que permitían el lucimiento de las mujeres jóvenes en los bailes de Carnaval y que he hallado en Valdeflores (Sevilla), El Ronquillo (Sevilla) y que también se daban en Nerva (Huelva). Estos disfraces sin máscaras o caretas coincidían en el baile con otras máscaras o mascaradas más o menos parecidas a las que acabamos de estudiar, con las que debían hacer un gran contraste ${ }^{43}$.

El atuendo de "Serrana" podía ser: peineta con flores en la cabeza, mantón de Manila, falda corta de volantes (más o menos por la rodilla), con estampados de flores y zapatillas de cintas para anudar en el tobillo. El modelo de "Praviana" o "Cazurra" solía inspirarse en las figuras femeninas que traen aún las etiquetas de ciertas botellas de anís, como el de "La Asturiana" o "La Castellanan. Una saya larga, con rayas verticales, o de

37. Caro Baroja, el Camaval, op. cit., pp. 182 y ss. Y 205 y ss.

36 GonzÁlez-Hontoria y otros, op. cit., p. 6.

39 J. Roma RuU, Aragón y el Carnaval, op. cit., p. 79.

to Caro Baroja, el Camaval, op. cit., pp. 264, 265, 282.

4 VV. AA., Camavals et Mascarades, op. cit., pp. 132 y 134.

\$2 Aparte de los informes de los folkloristas, la literatura española clásica ofrece ejemplos de mascaradas muy interesantes como la que sale en la Vida y bechos de Estebanillo González, ed. A. N. Zahareas y N. Spadaccini (Madrid: Castalia, 1978), pp. 382-384.

43 No es posible hallar fotografías de las otras máscaras. Pero sí de estos disfraces. He visto varias. Las muchachas posan en actitud elegante. 
fieltro negro, con festón o banda roja en la parte inferior; corpiño rojo, camisa blanca y pañuelo a la cabeza ${ }^{44}$.

Vamos a examinar ahora, más despacio, los nombres que reciben estos disfraces, dándole una importancia especial al de "Serrana*. Porque éste es un nombre de gran tradición en la literatura castellana, usado en la poesía desde muy antiguo para cierto tipo de mujeres que viven en las sierras y que tienen unos curiosos rasgos "primitivos": son de una extrana rusticidad, valientes hasta extremos nada propios en otras mujeres, y, en todos los casos, poseen un acusado apetito sexual. Todo esto se aprovecha para dar la nota cómica en Juan Ruiz, como es sabido ${ }^{45}$. Pero también, a partir del marqués de Santillana, y, sobre todo, del siglo xvi, estas serranas, que aparecen incluso en la prosa, se idealizan y se resentan como el modelo de la bella rústica. Así en Cervantes ${ }^{46}$, Lope de Vega ${ }^{47}$, Góngora ${ }^{48}$, por

44 Según mis informantes de Valdeflores (Sevilla) y fotos que he visto alli. En J. Caro Baroja, El Carnaval. op. cit., p. 386, en Valverde del Camino (Hueva) niños y niñas solían vestirse de "majos" o de "serranas" en los Jueves de Comadres y Compadres.

45 Parecidas a estas "serranas" se pueden encontrar bastantes ejemplos en libros conocidos como el de Dámaso Alonso, Poesía de la Edad Media y de tipo tradicional, o el de Margarita FRENK AlATORRe, Lírica española de tipo popular. O en el famoso romance de la Serrana de la Vera. CARO BAROJA tiene una interpretación especial de él en Ritos y Mitos equívocos (Madrid: Istmo, 1974), y también es interesante lo que dice en el Ensayo sobre la Literatura de Cordel (Madrid: Revista de Occidente, 1969), pp. 389 y 390 .

En la RDTP, I (1944), pp. 339 a 345 hay un informe de José de la Fuente sobre la costumbre de representar por Carnaval, en Guadilla de Villamar (Burgos), una pieza dramática en.verso donde encuentro un personaje llamado "serrana. con características similares a estas antiguas.

46 En La Galatea, ed. de Avalle-Arce (Madrid: Espasa-Calpe, 1987), p. 99. «(Galatea) Venía vestida a la serrana, con los luengos cabellos sueltos al viento, de quien el mesmo sol parescía tener embidia....

En Pedro de Urdemalas:

-Más que por nueuos niueles

lleuasse una de donceles

como serranas vestidos."

(Carlos Fernández GOMEZ, Vocabulario de Cervantes, Madrid, Real Academia Española, 1962. Voz "Serrano").

47 En El Príncipe despeñado. Obras escogidas (Madrid: Aguilar, 1987), 3. ed., p. 813 , donde se unen belleza y rusticidad. En El villano en su rincón (Madrid: EspasaCalpe, 1967), 3. ${ }^{2}$ ed., acto I, escena XIII, p. 151:

Fileto. Si quieres ver, señor, una serrana, hermosa como el sol... 
citar algunos ejemplos. El término tiene fortuna y llega hasta el siglo xIx, donde lo encontramos en costumbristas como Estébanez Calderón ${ }^{49}$ y en litografías ${ }^{50}$ con este carácter (como la titulada "Serrana vendiendo alfajores" en la Feria de Sevilla), siempre asociado a la hermosura de las mujeres rústicas. También se puede encontrar fácilmente en el cancionero popular del Sur y en el flamenco, con todos estos significados.

En el Carnaval del Norte de España no son desconocidos disfraces semejantes a estos de "Serrana", que tratan de dar prestigio a las jóvenes rústicas que los llevan. El más común de ellos tal vez sea el de "Madama" ${ }^{51}$, y también son conocidos los de "Dama" y otros.

En cuanto a los nombres de "Praviana" y "Cazurra": del primero, poco sé decir. Quizá hacen referencia a lugares del Norte de España tenidos por rústicos... Creo que es importante saber que la muchacha que se vestía de "Praviana" iba diciendo: "Flores, p'al mal de amores", mientras repartía las que llevaba en un canastillo ${ }^{52}$, porque este detalle subraya el carácter amoroso que veíamos que tenía también la "Serrana". "Cazurro" es un término relacionado directamente con el mundo rústico. Covarrubias lo trae con claro sentido sexual ${ }^{53}$, pero hoy generalmente significa abruto",

y en más lugares de esta obra misma. En otros aparece incluso al modo viejo de la Serrana de la Vera. En El Aldegüela, Obras escogidas, op. cit., tomo II, p. 20. En El Peregrino en su paria, en la égloga dedicada a Camila Lucinda que empieza: "Serrana hermosa..... En Los Pastores de Belén. Obras escogidas, op. cit., p. 1.398, donde la "serrana* es la Virgen. Y en el poema Virgen de la Almudena, donde también la Virgen es una "serrana". Etc.

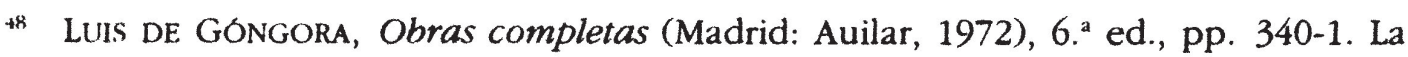
Virgen es una "serranaw. Ellas son protagonistas en el romance que empieza En los pinares de Xúcar, op. cit., pp. 148-150.

19 Escenas andaluzas, ed. González Troyano (Madrid: Cátedra, 1985); en la composición titulada "La niña en feria", p. 95.

5) De la serie Costumbres andaluzas, grabadas por Chaman. Lit. C. Santigosa. Sevilla.

51 El prestigio del término aparece reflejado en unas coplas de "marzas. recogidas en algún pueblo santanderino por M. García MaTos, y publicadas en su Magna antología del folklore musical de España, Hispavox, 1950.

-En esta casita hay una madama (bis), reluciente espejo, "tía. Quica se llama (bis).”

32 Ver nota 5.

\$3 Palabras cazurras son aquellas que "no se pueden pronunciar sin vergüenza del que las dice y del que las oye, como nombrar el miembro genital de uno y otro sexo...*. 
"zafio", "malicioso", ‘reservado", "poco hablador" ${ }^{54}$. También puede ser importante conocer el significado local que esta palabra tiene en el Vocabulario de Alcalá Venceslada: “CAZURRO: m. Así llaman en la provincia de Huelva a los naturales de Castilla la Vieja". Y "Cazurra" puede ser también, siguiendo siempre a Alcalá Venceslada, simplemente "vestido de mujer de pueblo" 55 .

Creo que el análisis de estas palabras, sobre todo el de :Serrana., permite decir que estos disfraces quieren realzar el atractivo de las muchachas de pueblo o aldea conforme a un modelo de hermosa rústica que tiene prestigio.

Otro aspecto curioso es que, tanto estos disfraces que yo he recogido como los similares que salen en Carnaval en el Norte de Espana, están relacionados con la danza o el baile. Veamos algunos ejemplos: en el libro de Nicolás Tenorio, La aldea gallega $a^{56}$, se nos informa de que, por Reyes, salía una pareja (el "danzante" y la "madama") a pedir el aguinaldo, bailando a la puerta de cada casa. El "danzante" viste de forma especial con pañuelos y cintas de colores y la "madaman lleva ael traje de una moza del pueblo que sea buenon. Según Fraguas ${ }^{57}$ en Cotobad (Pontevedra) son propias de Carnaval las "foliadas" o "momadas" donde intervienen "madamitas" y "madamitos". Ellos son "los mozos mejor plantados y que bailan con mayor perfección". Y de una chica muy arreglada se dice: "Vai que parece unha madamita" ${ }^{58}$. Unos y otras bailan "demostrando una seriedad protocolar que contrasta con la bufonería de los demás personajes" ${ }^{59}$. En Obona (Tineo, Asturias) también encontramos un "galán" y una "dama" que bailan, a primeros de año ${ }^{60}$. En la montaña leonesa, por Carnaval, salen "madamas": dos muchachos disfrazados femenilmente que

54 J. COROMINAS, Breve Diccionario etimológico de la lengua castellana (Madrid: Gredos, 1973), 3. ${ }^{\mathrm{e}} \mathrm{ed}$.

ss Vocabulario andaluz (Madrid: Gredos, 1980). También es conocida la costumbre de los asturianos de llamar "cazurros" a los leoneses. Por otra parte es curioso anotar que en Carnaval solían salir máscaras llamadas maragatos, valencianos, maños, etc. $\mathrm{Y}$ en las ciudades, negros, portugueses, castellanos, en el Siglo de Oro o en el Cádiz del S. xIx. Pero éstas son máscaras de otro tipo, masculinas, etc., y deben ser separadas de las que estamos comentando.

56 Nicolás Tenorio, La aldea gallega, op. cit., pp. 134 y ss.

57 Citado por Caro Baroja, el Camaval, op. cit., p. 223. A. Fraguas, O entroido nas terras do Sul de Cotobade", Nos, 15 de mayo de 1930, núm. 77.

58 RDTP, Il (1946), pp. 434 y ss., con el título de .Máscaras y sermones de Carnaval en Cotobad. En concreto las páginas 444 y 445.

s9 Caro Baroja, el Camaval, op. cit., p. 224.

60 Caro Baroja, el Carnaval, op. cit., p. 218. 
bailan ante las casas ${ }^{61}$. En Cataluña están el abonic" y la «bonica", dos niños vestidos con la mayor elegancia posible que bailan en la plaza ${ }^{62}$. También los disfraces de "Serrana", "Praviana" y "Cazurra" se usan para el baile de Carnaval y sus vestidos son tan formales como los de las "Madamas".

Otro aspecto importante de las "Serranas" y "Cazurras" de El Ronquillo (Sevilla) es que ambos disfraces eran objeto tradicional de "chotes" o "chotetes" ${ }^{63}$, golpes o fustigaciones que los muchachos, armados de finas varas, acostumbraban a dar en las piernas a las muchachas así disfrazadas, en el baile de Carnaval, con la intención de que saltasen y-dicen mis informantes - "se les pudiese ver las piernas", costumbre que era conocida con el nombre de «jugar a refajitos cortos". Parece importante subrayar que estas fustigaciones son conocidas como comunes en el Carnaval, además de que, a veces, aparecen en relación con el baile y los hermosos vestidos ${ }^{64}$.

4) Veamos ahora las farsas o pequeñas representaciones bufas que he encontrado con el nombre común de "juegos de Carnaval" en las aldeas de El Cañuelo, Arroyo en la Plata, El Peralejo y la Alcornocosa (todas en la provincia de Sevilla).

Estas "Comediejas de color y sabor insustanciales", como dice C. Cabal ${ }^{\circ 5}$, son, en cambio, de una gran importancia para el etnógrafo. Tal es, al menos, el parecer de Caro Baroja, que señala su abundancia en España, aunque, al mismo tiempo, adiverte que de ellas se tiene una apenadora "parvedad de conocimientos" ${ }^{66}$.

Ya la expresión "juegos de Carnaval" parece un arcaísmo, semejante a "juegos de escarnio" ${ }^{67}$. "Juegos de Andalucía, como entremeses, en prosa"

(1) CARO BAROja, El Camaval, op. cit., p. 231.

62 Caro Baroja, el Carnaval. op. cit., pp. 248 y 249.

63 En Rute (Córdoba) encuentro un juego carnavalesco llamado "chutete», sin más aclaraciones, en la Guia de Fiestas Populares de Andalucía, Junta de Andalucía, Consejería de Cultura, Sevilla, 1982, p. 306. Corominas, en el conocido resumen del Diccionario, trae "Choto", 1335, "cabrito que mama" u "otros animales lactantes". La palabra, a su juicio, es onomatopéyica, "por imitación del ruido que hace el animal al chupar de las ubres.

o Violant i Simorra, el Pirineo español, op. cit., p. 573. Caro Baroja, el Camaval, op. cit.; Segunda Parte, cap. XII y Tercera Parte, cap. X.

65 Caro Baroja, el Camaval, op. cit., p. 218.

to Caro Baroja, el Camaval, op. cit., p. 218.

6. Ver, por ejemplo, Francisco López ESTRADA, «Manifestaciones festivas de la literatura medieval castellana", en Formas carnavalescas en el arte y la literatura, del Serbal, Barcelona, 1989, pp. 104, 105, 106. También la expresión .juegos escénicos. usada por Jovellanos en la Memoria para el arreglo de la policía de los espectáculos y diversiones públicas. y sobre su origen en España, ed. de José Lage, en Cátedra, Madrid, 1979, pp. 100 y ss. 
se titula un interesante texto de Francisco Antonio de Bances Candamo, de su libro titulado Theatro de los theatros de los passados y presentes siglos. Historia scénica griega, romana y castellana: preceptos de la Comedia Española ${ }^{68}$. Ese autor (1662-1704) asturiano, que estudió y vivió en Sevilla, usa, para ciertas representaciones teatrales como las que estamos viendo, la palabra "juegos". Advierte su aire arcaico y los asemeja a los que hacían - dice- los antiguos griegos ${ }^{69}$. A pesar de que le molesta su indecencia, dada la importancia que les concede, resume dos, vistos por él personalmente en Osuna (Sevilla). Parece que estos ajuegos" no se hacían en ninguna fecha especial, sino "quando en los lugares del Reino de Sevilla se juntan a sus solaces los mozos y las mozas" ${ }^{70}$, y para "entretener parte de las noches" ${ }^{71}$.

En el primero aparece un estudiante hambriento que encuentra una viña sin guarda. En la mitad del banquete es sorprendido por el vigilante que lo amenaza con el arcabuz y le pide el dinero que vale la fruta. El estudiante se excusa de no tenerlo y el guarda le hace devolver las uvas que había comido. Pasado esto, uno y otro llegan a hacerse amigos y, en un descuido, el estudiante arrebata el arma al guarda, a quien obliga "a comer las ubas que el estudiante havía dejado" ${ }^{72}$. El segundo presenta a la mujer de un escultor recibiendo la visita de un sacristán que trae, al parecer, la estatua de un santo que tiene una pierna rota, para que el escultor la arregle, y que viene cubierta con una sábana para evitar su deterioro en el traslado. Cuando se han ido el sacristán y sus acompañantes, la mujer, curiosa, levanta la sábana y se encuentra con aun deshonesto mozo todo desnudo" ${ }^{73}$. Cita otros ‘juegos" más, que no resume, por muy conocidos y más desvergonzados seguramente: «el soldado, la sortija, el Padre Prior y otros más licenciosos de lo que devieran, como el del palillo y el alfiler, que ya conocerá el que los supiere, y el que no, mejor será que no los conozca" ${ }^{74}$.

68 El texto lo encuentro en Antología del entremés barroco, ed. de Celsa Carmen García Valdés, edit. Plaza y Janés, Barcelona, 1985, pp. 525, 526 y 527.

69 .Esta especie de Representación también nos ha quedado en unos juegos que se vsan oi en Andalucía, cuia forma referiré aquí para que se coteje con los antiguos el siglo presente y se vea que el mundo siempre ha sido uno y que pocas invenciones ai en él que, aunque parezcan nuevas, no ocurran más a la memoria de los hombres que a su discurso" y les reconoce que atienen algunos destos quentos dialógicos su especie de invención no poco festivar. Op. cit., pp. 525 y 526.

70 Celsa Carmen GaRcía Valdés, Antología del entremés barroco, op. cit., p. 525.

71 Celsa Carmen García VAldÉs, Antología del entremés barroco, op. cit., p. 525.

72 Celsa Carmen Garcia Valdés, Antología del entremés barroco, op. cit., p. 526.

73 Celsa Carmen Garcia Valdés, Antología del entremés barroco, op. cit., p. 527.

74 Celsa Carmen García VAlDÉs, Antología del entremés barroco, op. cit., p. 525. 
Todo esto debía ser muy común en ciertas zonas andaluzas (y especialmente interesante en Carnaval). Arcadio de Larrea, hablando del teatro popular en España, dice:

\begin{abstract}
"Me habían hablado en Andalucía de los juegos o "juguetillos"; luego hallé que Lafuente y Alcántara los describe como "juegos de cortijo". Se celebra baile y, en un momento cualquiera, un nuevo personaje, que antes ha de haber desaparecido con cierto misterio de la reunión, y ha estado con otros en apartado lugar tramando no se sabía qué, se presenta y dice: juego ... Empieza ... con una especie de introducción o escena preliminar, reducida a un breve diálogo, que ha de terminar con algún chiste ... Esto se llama entrada de juego, y generalmente no tiene conexión ninguna con la escena que ha de representarse después. En esta última sólo hay premeditado y convenido el asunto principal y el desenlace; el diálogo y demás incidencias son improvisados por los actores.. Relata varios de ellos -continúa Larrea refiriéndose a Lafuente y Alcántara- entre otros el del "galápago* y el del alicenciado" ${ }^{75}$
\end{abstract}

El mismo Arcadio de Larrea cita algún escrito no especificado de Luis Montoto donde se da cuenta de otros "juegos" como el de "la zorra, las gallinas y el perro» y otros diecinueve más, y de sus personajes más comunes, tales como el "Licurgo o sabidillo, el fanfarrón, el alcalde, el sacristán, el estudiante, el médico, el rústico, el bobo y el diablon ${ }^{76}$. Sigue Larrea con citas sin especificar de Montoto, y en una de ellas afirma que "muchos juegos tienen por fin último una burla, una chanzoneta contra uno o más espectadores, a quienes se convierte en actores... y que en algunos todo el público es objeto de esas burlas" 77 .

El Carnaval es el tiempo adecuado para todos los juegos. Sean en el sentido general ${ }^{78}$ o en este especial de representaciones teatrales breves, como entremeses, etc., pero todo relacionado con burla y risa. Ya en la famosa tabla de Brueghel, el viejo, llamada "El combate entre el Carnaval y la Cuaresma" (Kunsthistorisches Museum de Viena, 1559), se pueden observar las representaciones de dos conocidas farsas: la de las "Bodas de

75 Arcadio de LARREa Palacín, "El teatro popular en España", en El Folklore español, varios autores. Editado por J. M. GÓmEZ-TABANERA, Instituto Español de Antropología Aplicada, Madrid, 1968, p. 351. Nótese que solían representarse en los bailes. Así, ya he dejado dicho que en Almadén de la Plata (Sevilla), .juego de Carnaval. es expresión sinónima de "Baile de Carnaval.

"6 Arcadio de larrea Palacín, .El teatro popular en España", op. cit., p. 351.

7 Arcadio de Larrea Palacf́, "El teatro popular en España, op. cit., p. 352.

78 José Blanco White, Cartas de España, Alianza, Madrid, 1972. Carta novena, pp. 209 y ss. Blanco reconoce que hay un cierto encanto en estos restos de antigua sencillez. Creo que esta opinión se puede encontrar también en Rodrigo Caro, en sus Dias geniales o lúdricos. 
Mopso y Nisa" y la evocación burlesca del encuentro caballeresco entre Orson y Valentin, del ciclo de Carlomagno ${ }^{79}$.

Para corroborar esto se pueden traer muchos textos del teatro del Siglo de Oro. Veamos éste, perteneciente al entremés de Calderón, titulado, precisamente, Las Carnestolendas:

VEJETE No hay quien no tema en las Carnestolendas:

el capón teme muerte supitaña,

el gallo ser corrido en la campaña,

el perro, de la maza el desconcierto,

las damas, de que el perro sea muerto,

las estopas de verse chamuscadas,

las vejigas de verse aporreadas,

la sartén si su tizne alguno pringa,

el agua que la sorba la jeringa,

el salvado de andar siempre pisado,

siendo a un tiempo salvado y condenado.

Cercadas nuestras ganas estos días

de ejércitos de mil pastelerías,

$y$ tal hambre en el cerco padecemos

que hasta las herraduras nos comemos.

María Mas todo, padrecito, se remedia.

VEJETE ¿Con qué, hijitas rollonas?

LAS DOS Con comedia ${ }^{80}$.

Se pueden multiplicar las referencias a esta costumbre de representar farsas por Carnaval con los informes etnográficos -espanoles y europeos en general- en la mano. Pero, repasemos, finalmente, las que yo he documentado.

En primer lugar, vemos cómo la venta burlesca del burro, una vieja mascarada de carácter muy campesino, es usada para estos ajuegos de Carnaval. Aunque en algún caso (El Peralejo, Sevilla) se sustituye el burro por el oso, la mascarada del oso no parece poderse incluir aquí, porque no era representada de manera tan formal, en un recinto cerrado, de noche sólo, en el baile de Carnaval, etc., ni mis informantes la han clasificado nunca como uno de estos ajuegos".

Por otro lado, encuentro un número mayor de escenas ya más parecidas al entremés. La del cura y el cabrero bruto, o la de la vieja mandona,

79 Para ver el sentido de estas farsas, Camavals et mascarades, op. cit., pp. 15, 16 y 17.

80 En la Antología del entremés barroco, op. cit.

81 Miguel Ángel Pérez Priego, Teatro renacentista, ed. Plaza y Janés, Barcelona, 1986. Ver la .Farsa del Molinero* de Diego Sánchez de Badajoz, pp. 191 y ss. 
que se representaban en El Cañuelo y en Arroyo de la Plata, se relacionan bien con todo ese mundo. Ya en el teatro renacentista se pueden encontrar los personajes del clérigo y el pastor juntos, con este mismo aire burles$\mathrm{co}^{81}$. El tipo de viejo mandón es común también. En el entremés de Cervantes, El viejo celoso, donde dice Cristina: "Jesús y qué mal viejo! Toda la noche: Daca el orinal, toma el orinal, levántate, Cristinica, y caliéntame unos paños, que me muero de la ijada; dame aquellos juncos, que me fatiga la piedra ${ }^{82}$. En La Alcornocosa, un personaje llegaba a una viña y comenzaba a comer uvas, repartiéndolas incluso entre el público. Este arranque tal vez pueda relacionarse con uno de los «juegos" que Francisco A. de Bances había hallado en Osuna.

Sería de desear que se recogieran muchas más de estas comedietas o "juegos de Carnaval" que en ciertas partes de Andalucía deben poderse encontrar aún con abundancia. Sobre todo de las relacionadas con el mundo que han manejado, desde hace siglos, los autores de entremeses y todo este tipo de teatro que quizá tenga un aire más urbano y moderno.

5) Para finalizar, sólo apuntar que, de las máscaras de "gitanos", encuentro muchas referencias en el libro de El Carnaval ${ }^{83}$. Asimismo de las de "locos", de la del "ciego y el lazarillo" y de las de "cabreros" o pastores ${ }^{84}$.

Violant i Simorra recoge un entierro del Carnaval en Agullana (Alto Aragón), donde el Miércoles de Ceniza llevaban a un hombre en andas, "tendido en una escalera de mano", a la plaza, "donde se celebraba un simulacro de sentenciarlo a muerte ${ }^{85}$. Algo similar he recogido en Santa Ollala del Cala (Huelva). Una mujer hacía de muerta, tumbada en una escalera que llevaban dos, a modo de camilla. Otra mujer, enmascarada ridiculamente, y que se supone la madre de la muerta, pedía limosna para el entierro.

Finalmente, creo que puede ser provechoso estudiar de cerca los cedazos y las zarandas o harneros, instrumentos que se encuentran - no sólo en mi colección - unidos a máscaras carnavalescas, y que han tenido

82 Miguel de Cervantes, Entremeses, ed. de Nicholas Spadaccini. Cátedra, Madrid, 1988. Más viejos de éstos: Fermín Bouza-Brey, "Teatro de Camaval en Galacian, en la Retista de Dialectología y Tradiciones Populares, V, 1949.

*3 Julio Caro Baroja, El Camaval. op. cit., pp. 131, 180, 183, 199, 245, 246, 248, 251,271

84 Julio Caro Baroja, El Carnaval, op. cit., pp. 187, 202, 218, 251, 256. Ver también en A. Fraguas, "Máscaras y sermones de Carnaval en Cotobad,, op. cit., p. 442.

.5 Ramón Violant I Simorra, El Pirineo español, op. cit., p. 570 . Es curioso que el detalle de la escalera figura, también referido al Carnaval, en la Sevilla de Blanco White. Ver sus Cartas de España, op. cit., carta novena, p. 213. 
relación con la magia. También han aparecido en el teatro (de entremeses en general o de Carnaval en particular) y, sobre todo, en determinadas danzas ${ }^{86}$.

Francisco M. PÉrez Carrera

Instituto de Formación Profesional de Camas Sevilla

Colección de máscaras y mascaradas de Carnaval de pueblos de Sierra Morena pertenecientes a las provincias de Huelva y Sevilla, y recogida de los recuerdos de los informantes referidos a los años 1915-1936 aproximadamente. Estudio comparado con otras áreas de España y de Europa, con criterios espaciales y temporales.

Carnival mask and masquerade collection belonging to Sierra Morena villages in the provinces of Huelva and Seville, and picked up from memories of the informants relating to the years 1915-1936 approximately. Comparative survey with other Spanish and European areas, based on space and time criteria.

86 Índice de informantes:

Arroyo de la Plata (Sevilla). Don Manuel Gómez Pérez, nacido en 1898. Doña Carmen González Domínguez, nacida en 1922. Don Andrés Díaz López, nacido en 1922 y su mujer doña Rosario Rodríguez Cabeza, nacida en 1926 y su hijo Andrés.

Valdeflores (Sevilla). Doña Carmen y doña Marcelina Fernández, nacidas en 1920 aproximadamente.

Villargordo (Sevilla). El señor Antonio, de 70 años en 1982. Calle única, núm. 5; su mujer y sus dos cuñadas.

La Alcomocosa (Sevilla). Doña Isabel Pereira Moreno, nacida antes de 1921 y su vecina, de 80 años en 1991.

El Castillo de las Guardas (Sevilla). Don Andrés Díaz López y doña Rosario, su mujer, citados más arriba.

El Cañuelo (Sevilla). Don Francisco Domínguez y su mujer doña Francisca. Los dos de 72 años en 1984.

El Peralejo (Sevilla). Don Nicolás Domínguez.

Santa Olalla del Cala (Huelva). Doña Ascensión Miranda Escobar, de 69 años en 1988.

El Ronquillo (Sevilla). El señor Cipriano, que vive en la calle Queipo de Llano y el señor Ramón, de la calle Carlos Cañal. Ambos mayores de 70 años en 1987. A todos, las gracias. 